\title{
Investigation of Specifics of Self-Management towards Dealing with Cancer Pain among Adult Outpatients
}

\author{
Masako Yamanaka1,2 \\ ${ }^{1}$ Department of Nursing Science, Faculty of Health Care, Tenri Health Care University, Nara, Japan \\ ${ }^{2}$ Doctoral Program, Graduate School of Nursing, Osaka Medical College, Osaka, Japan \\ Email: m.yamanaka@tenriyorozu-u.ac.jp
}

How to cite this paper: Yamanaka, M. (2018) Investigation of Specifics of Self-Management towards Dealing with Cancer Pain among Adult Outpatients. Health, 10, 1520-1538. https://doi.org/10.4236/health.2018.1011116

Received: October 24, 2018

Accepted: November 19, 2018

Published: November 22, 2018

Copyright (c) 2018 by author and Scientific Research Publishing Inc. This work is licensed under the Creative Commons Attribution-NonCommercial International License (CC BY-NC 4.0). http://creativecommons.org/licenses/by-nc/4.0/

\begin{abstract}
Purpose: This study aimed to identify specifics of self-management towards dealing with cancer pains among adult outpatients. Methods: Semi-structured interviews were conducted with 16 adult outpatients ( 9 males and 7 females) who suffered from cancer pain and the data obtained were analyzed using the qualitative synthesis method of KJ Ho. Results: An analysis of the results revealed these key findings for the following symbolic wording of the semi-structured interviews: Cooperative relationship with medical professionals; Problems originating from cancer pain; Self-regulation of analgesic medications based on the interactions with medical professionals; Self-regulation of the analgesic medications based on the physical perceptions of the effects; Self-regulation to maintain a balanced and calm mind, Fulfilling life by the pain alleviation and liberation from the restrictions imposed by the cancer; and Efforts to maintain their lives by themselves. Conclusion: Based on the cooperative relationship established with medical professionals, the patient carried out the self-regulation of cancer pain using analgesics, and self-regulation to maintain a balanced and calm mind. Nurses must therefore sufficiently educate patients regarding how to communicate successfully with medical professionals in order to improve cancer patients' pain management regarding both physical and mental aspects.
\end{abstract}

\section{Keywords}

Self-Management, Cancer Pain, Adult Outpatients

\section{Background}

In Japan, approximately $60 \%$ of outpatients with advanced cancer suffer from 
pain, and among these approximately $20 \%$ have reported moderate to severe pain, and overall about 50\% suffer from physical and mental pain [1]. Cancer pain relief rates among outpatients are statistically significantly lower than that of inpatients, and the symptom prevalence rate of patients younger than 65 years of age is significantly higher than that of patients 65 years or older [2]. These reports suggest that adult outpatients with cancer suffer from pain due to the cancer. Adulthood is the most active period in life playing a leading role in society. For this reason, it is an important challenge for nurses to assist adult outpatients in alleviating cancer pain and to support daily living and social activities.

The Oncology Nursing Society has added self-management as one of the research topics to be prioritized [3]. With self-management, patients with cancer can work towards achieving goals because they are empowered in the partnership with medical professionals [4]. This makes it important for patients with cancer pain to have own self-management skills to deal with the various problems arising from cancer induced pain for them to become able to live their lives at home, away from the hospital. In cancer pain there are, however, aspects of mental anguish affected by envisioning the progress and eventual death by the cancer, as well as the pain arising from the physical state. It is also reported that patients are unable to properly use analgesics due to concerns about and misunderstanding of the workings of opioid analgesics [5]. As described above, cancer pain is a complex pain involving the influence of opioid analgesics, and it is necessary for medical professionals to assist cancer outpatients with cancer to be able to effect self-management. Previous studies that investigated patients with cancer pain have reported the awareness of opioid analgesics [6], the relationship between awareness of opioid analgesics and adherence to these [7], difficulties in the pain management and also in the subjective efforts [8], the management of medication [9], the self-management for patients from the point of view of experts in palliative care [10], and also the relationship between cancer pain and quality of life [11]. However, there have been no studies that investigated and detailed the experiences of outpatients detailing the self-management to alleviate cancer pain. It is important to understand how patients manage cancer pain to help adult outpatients individually cope with the various problems arising from cancer pain at home and at work.

\section{Purpose of the Study}

This study aims to identify specifics of self-management towards dealing with cancer pain among adult outpatients.

\section{Definition of Terms}

\section{Self-Management of Cancer Pain}

Referring to the definition by Yamanaka [12], self-management of cancer pain was defined as "the process in which patients with cancer pain make the decision to manage their pain, enhance their self-efficacy by solving problems caused by 
pain, and incorporate pain-relieving strategies into daily life, through interactions with healthcare professionals."

\section{Methods}

\subsection{Design}

This study employs a qualitative and inductive design using the qualitative synthesis method of KJ Ho (QSM-KJHo) [13], and is compliant with the basic principles and techniques of the KJ-Ho [14] [15], a creative problem solving technique proposed by a cultural anthropologist, Jiro Kawakita (1920-2009). The QSM-KJHo is a qualitative analysis technique which was theoretically established by Yamaura [13], who engaged in the research into and dissemination of KJ-Ho for many years, with results that have been widely used in nursing sciences in Japan because it enables an understanding of the actual condition in various settings and provides approaches to solve problems. The QSM-KJHo is able to understand the whole image as part of a logical structure by integrating apparently chaotic descriptive data. The QSM-KJHo method also makes it possible to understand the structure of the whole image of self-management of cancer pain by integrating the data of individual patients regarding how they manage the various problems arising from mental aspects, daily life and social activities as well as deal with the physical problems due to cancer pain. For this reason, the present study employed the QSM-KJHo analysis.

\subsection{Participants}

Participants of the study are adult outpatients with cancer pain. Participants in the study were adult outpatients suffering from cancer, and the inclusion criteria were that they were cancer patients (30 to 69 years of age), with the cancer pain persisting for more than one month, that the pain was nociceptive pain and/or neuropathic pain caused by metastasis or infiltration of the cancer, that communication by speaking was possible, with Performance Status 0 to 3, and that they were able to maintain a seated position for about 30 to 45 minutes for the interview. The exclusion criteria of the study were visual impairment, hearing impairment, cognitive impairment, and mental disorders.

The researcher recruited participants at three designated cancer hospitals in Osaka Prefecture. The researcher requested approval by physicians of the facilities to collect data and to select potential patients for participation, and the researcher verified that the inclusion criteria were met. The researcher obtained patient consent to participate in the study by explaining details of the study orally using the survey document. Some potential patients were introduced by nurses of outpatient departments, and in this case, the procedures described above were used after obtaining approval by the physicians in charge of the patients.

\subsection{Data Collection}

The data were collected from July of 2017 to February of 2018 through 
semi-structured interviews. A semi-structured interview for 30 to 45 minutes per session were conducted to participant each for data collection by the researcher using an interview guide created based on the definition of self-management of cancer pain. The interview guide included details of the goals of pain relief, influence of pain on daily life and social activities, the influence on emotions, efforts to cope with the influence of pain on life and emotions, specifics of how to interact with medical professionals and family members, and situations and ways of evaluation of the use of analgesics. The researcher requested participants to talk freely during the interviews. The interviews were conducted in a room where privacy could be protected, and the statements of the interview were recorded on an electronic recording device with the permission of the participants. The researcher transcribed the narratives from the recorded data.

\subsection{Data Analysis}

The transcribed data were analyzed using the QSM-KJHo [13]. The researcher analyzed the transcript for each participant separately, and then integrated the data of all participants. Figure 1 shows the following data analysis steps 1) to 3 ). The analysis was performed in the following manner:

1) Label making: The researcher extracted statements related to the self-management of cancer pain from the transcripts. These extracted statements were segmented into phrases by meaning, and assigned labels.

2) Collection of labels and nameplate creation: Reading the descriptions assigned to the labels, literally, phrase by phrase, the researcher collected labels with similar meanings and background issues from among the descriptions, and created nameplates to be able to write a sentence that represents and substantiates the fullness of the meaning of the collected labels in a new label.

3) Group forming: Including the new labels that were added, the researcher repeated the procedure of "collection of labels and nameplate creation". In the process of repeating this procedure in a stepwise manner, the researcher paid attention to create nameplates that became increasingly abstract but remained concrete and specific. Group forming was considered complete when no similar labels were left and it became impossible to integrate labels further. Next, the researcher confirmed whether the description of the final labels remaining in the final stage of the group forming represented the reality as imagined by the participants. In the separate analysis for each of the participants, the final labels were extracted after 4 to 6 stages of group forming.

4) Integrated analysis: After performing steps 1) to 3) as described above for each participant, the researcher performed the integrated analysis to integrate the different labels of all the participants. In this analysis, the researcher returned to the group forming two stages prior to the last in the separate analysis, and retained use the labels that were not overly abstract for the further analysis. Using these labels, the researcher continued group forming in a stepwise manner until final labels were extracted. 


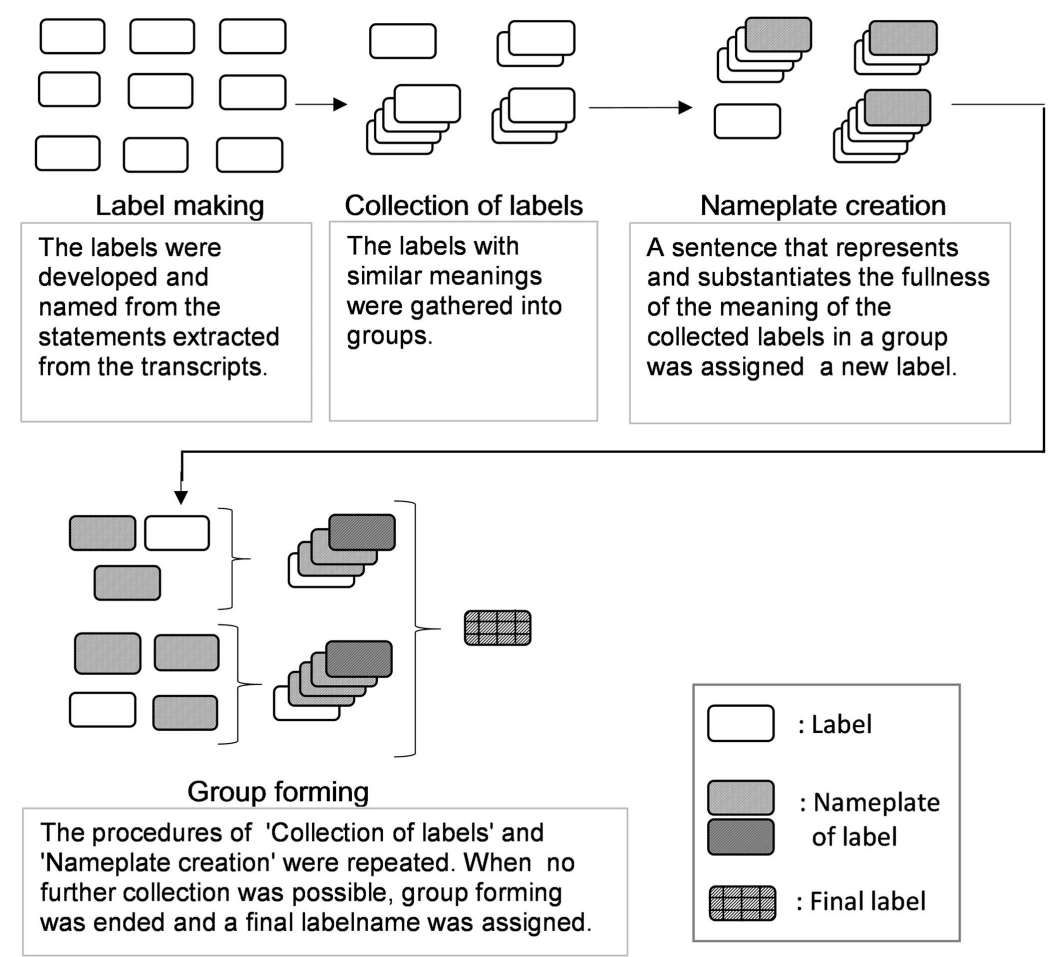

Figure 1. Label making to group forming of the date analysis steps.

5) Spatial arrangement: The researcher arranged the final labels extracted in the integrated analysis according to the overall impression provided by the final labels and the relations among them, and expressed this schematically. Further, the researcher added a symbolic wording that briefly indicates what the label of the final stage expresses.

\subsection{Ensuring Rigor}

In this study, the researcher introduced a standard to ensure the trustworthiness of this qualitative research [16]. To enhance credibility, the researcher employed the QSM-KJHo, which has been theoretically established as a qualitative analysis technique. The researcher conducted surveys at three facilities to include a broad range of participants, and ensured that age and gender would not be biased. The attitude of the researcher was assumed to be one of showing sympathetic understanding and unconditional acceptance so that the participants could speak frankly in the interview. When the meaning of statements of participants was ambiguous, the researcher confirmed the interpretation of the statements during the interview. The researcher underwent QSM-KJHo training several times and has experience in conducting qualitative research. During the process of the analysis, the researcher was under the supervision of researchers specializing in qualitative research and cancer nursing, and the results of the analysis were examined with graduate students of a doctoral program. To enhance transferability of the results, the data collection period, the number of participating facilities, the number of participants and their demographic characteristics, the data col- 
lection method, and the length of the interviews are described in this paper. To enhance dependability, the study design, survey particulars, and the method of the analysis are also described in this paper. To enhance confirmability, the faculty of the doctoral program of the institution of the author supervised the whole study.

\subsection{Ethics}

This study was conducted with the approval of the Research Ethics Committee of Osaka Medical College (No. Nurs-58) and the approval of the Research Ethics Committee of the facility where the data were collected (No. 607). The researcher explained prospective participants about the following items orally using written explanations: the significance, purpose, and methods of the study, freedom of participation and withdrawal, handling of personal information, method of data storage, considerations for the mental and physical burden, and publication of the study results. Participants expressed consent in writing. Interviews were conducted using the waiting time prior to treatment and payment for hospital charges, and the researcher paid careful attention to the mental and physical conditions of the participants.

\section{Results}

\subsection{Participants}

The number of participants is 16 (9 males and 7 females) (Table 1$)$. The mean age was 58.6 years $(S D=8.9)$, the mean length in months after the diagnosis of cancer was 62.2 months ( 1 - 342 months), the mean duration of pain due to the cancer was 18.5 months (2 - 65 months), and all 16 participants were administered opioid analgesics. The total number of interviews was once per participant, and the mean length of the interviews was 39.9 minutes (18 - 88 minutes).

\subsection{Structure of Self-Management for Cancer Pain among Adult Outpatients}

The researcher analyzed the data collected through semi-structured interviews in a stepwise manner using QSM-KJHo, and as a result, the data were integrated into 7 final labels and a schematic diagram of the spatial arrangement was created (Figure 2). The symbolic wordings are printed in "bold" in this paper.

The statements of the adult outpatients that explained the structure of the self-management for cancer pain are as follows: Patients experienced problems in their daily life due to pain and side effects of the opioid analgesics, as well as a decline in motivation due to the pain, as problems originating from cancer pain. For this reason, based on the cooperative relationship with medical professionals who share the perceptions of cancer pain and analgesics, patients have conducted self-regulation of analgesic medications based on the interactions with medical professionals, and self-regulation of the analgesic medications based on the physical perceptions of the effects, as well as 
self-regulation to maintain a balanced and calm mind to the problems originating from cancer pain. In self-regulation of analgesic medications based on the interactions with medical professionals, patients regulated their own analgesic medications and side effects by themselves according to their own social activities. In self-regulation of the analgesic medications based on the physical perceptions of the effects, patients regulated the analgesic medications by deciding their own tolerance to pain due to their own concerns about

Table 1. Overview of participants.

\begin{tabular}{|c|c|c|c|c|c|c|c|c|c|c|c|}
\hline ID & Sex & Age & $\begin{array}{l}\text { The family } \\
\text { who lives } \\
\text { together }\end{array}$ & work & Primary & $\begin{array}{c}\text { The duration } \\
\text { from cancer } \\
\text { diagnosis } \\
\text { (months) }\end{array}$ & $\begin{array}{l}\text { The duration } \\
\text { of cancer } \\
\text { pain } \\
\text { (months) }\end{array}$ & $\begin{array}{c}\text { Cause } \\
\text { parts } \\
\text { of cancer } \\
\text { pain }\end{array}$ & $\begin{array}{l}\text { The kind of } \\
\text { pain }\end{array}$ & Analgesics & Treatment \\
\hline A & M & 60 's & $\bigcirc$ & - & Lung & 17 & 11 & Bone & nociceptive & Oxycodone & Chemotherapy \\
\hline B & M & 60 's & $\bigcirc$ & Worker & Lung & 6 & 6 & $\begin{array}{l}\text { Lymph } \\
\text { node }\end{array}$ & nociceptive & $\begin{array}{c}\text { NSAIDs and } \\
\text { Tramadol }\end{array}$ & Radiotherapy \\
\hline $\mathrm{C}$ & M & 40 's & $\bigcirc$ & - & Lung & 24 & 24 & Bone & nociceptive & $\begin{array}{c}\text { NSAIDs and } \\
\text { Tramadol }\end{array}$ & $\begin{array}{c}\text { Palliative care } \\
\text { alone }\end{array}$ \\
\hline $\mathrm{D}$ & M & 60 's & - & Homemaker & Lung & 43 & 14 & Bone & nociceptive & $\begin{array}{l}\text { NSAIDs and } \\
\text { Fentanyl }\end{array}$ & Chemotherapy \\
\hline $\mathrm{E}$ & M & 50 's & $\bigcirc$ & - & Lung & 87 & 24 & Lung & nociceptive & $\begin{array}{l}\text { NSAIDs and } \\
\text { morphine }\end{array}$ & Chemotherapy \\
\hline $\mathrm{F}$ & M & 50 's & - & $\begin{array}{l}\text { Worker and } \\
\text { Homemaker }\end{array}$ & Lung & 45 & 9 & Bone & nociceptive & $\begin{array}{l}\text { NSAIDs and } \\
\text { Oxycodone }\end{array}$ & Chemotherapy \\
\hline G & M & 60 's & $\bigcirc$ & - & Lung & 6 & 8 & Lung & nociceptive & $\begin{array}{l}\text { NSAIDs and } \\
\text { Tapentadol }\end{array}$ & $\begin{array}{c}\text { Palliative care } \\
\text { alone }\end{array}$ \\
\hline $\mathrm{H}$ & M & 60 's & - & Homemaker & Lung & 52 & 5 & Pancreas & $\begin{array}{l}\text { nociceptive } \\
\text { and } \\
\text { neuropathic }\end{array}$ & $\begin{array}{c}\text { Fentanyl and } \\
\text { Pregabalin }\end{array}$ & Chemotherapy \\
\hline I & M & 50 's & $\bigcirc$ & Worker & Pleura & 26 & 26 & Pleura & nociceptive & $\begin{array}{l}\text { NSAIDs and } \\
\text { Methadone }\end{array}$ & Chemotherapy \\
\hline $\mathrm{J}$ & $\mathrm{F}$ & 60 's & $\bigcirc$ & Worker & Lung & 138 & 54 & Bone & nociceptive & $\begin{array}{l}\text { NSAIDs, } \\
\text { Acetaminophen } \\
\text { and Tapentadol }\end{array}$ & Chemotherapy \\
\hline $\mathrm{K}$ & $\mathrm{F}$ & 50 's & $\bigcirc$ & Homemaker & Breast & 1 & 2 & $\begin{array}{l}\text { Breast and } \\
\text { lymph node }\end{array}$ & nociceptive & $\begin{array}{l}\text { NSAIDs and } \\
\text { Oxycodone }\end{array}$ & Chemotherapy \\
\hline $\mathrm{L}$ & $\mathrm{F}$ & 40 's & $\bigcirc$ & Homemaker & Breast & 95 & 12 & Bone & nociceptive & $\begin{array}{l}\text { NSAIDs and } \\
\text { Oxycodone }\end{array}$ & Chemotherapy \\
\hline M & $\mathrm{F}$ & 50 's & $\bigcirc$ & Homemaker & Breast & 72 & 65 & Bone & $\begin{array}{l}\text { nociceptive } \\
\quad \text { and } \\
\text { neuropathic }\end{array}$ & $\begin{array}{c}\text { NSAIDs, } \\
\text { Oxycodone and } \\
\text { Pregabalin }\end{array}$ & Chemotherapy \\
\hline $\mathrm{N}$ & $\mathrm{F}$ & 40 's & $\bigcirc$ & Homemaker & Breast & 37 & 26 & Bone & nociceptive & $\begin{array}{l}\text { NSAIDs and } \\
\text { Tramadol }\end{array}$ & Chemotherapy \\
\hline $\mathrm{O}$ & $\mathrm{F}$ & 60 's & - & Homemaker & Breast & 342 & 6 & Bone & $\begin{array}{l}\text { nociceptive } \\
\text { and } \\
\text { neuropathic }\end{array}$ & $\begin{array}{l}\text { Tramadol and } \\
\text { Pregabalin }\end{array}$ & $\begin{array}{l}\text { Endocrine } \\
\text { therapy }\end{array}$ \\
\hline $\mathrm{P}$ & $\mathrm{F}$ & 60 's & $\bigcirc$ & - & $\begin{array}{c}\text { Gall } \\
\text { bladder }\end{array}$ & 3.5 & 4 & $\begin{array}{l}\text { Gall bladder } \\
\text { and bone }\end{array}$ & nociceptive & $\begin{array}{l}\text { NSAIDs and } \\
\text { Oxycodone }\end{array}$ & Chemotherapy \\
\hline
\end{tabular}




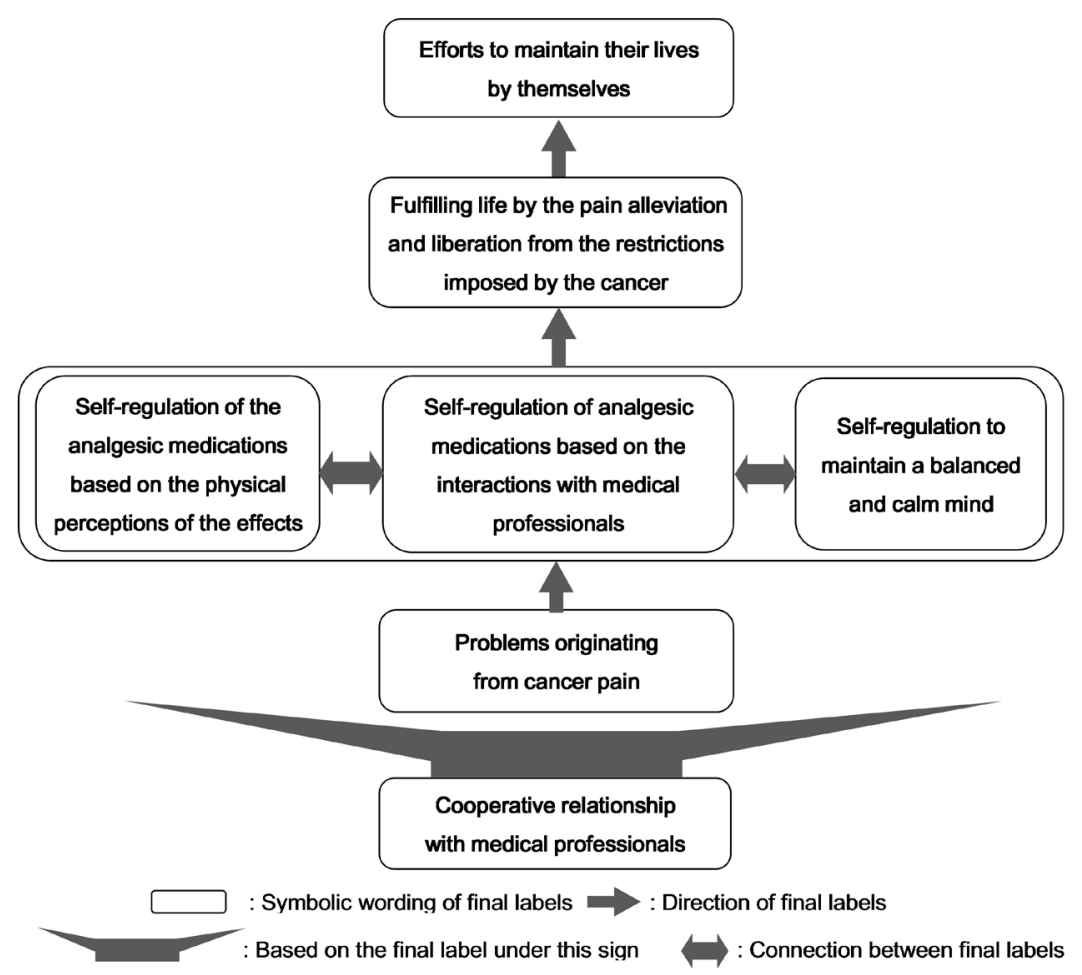

Figure 2. Structure of self-management for cancer pain among adult outpatients.

the tolerance to opioid analgesics. In self-regulation to maintain a balanced and calm mind, patients were trying to think about matters positively to stay calm. Through these efforts, with a fulfilling life by the pain alleviation and liberation from the restrictions imposed by the cancer, patients were making efforts to maintain their lives by themselves holding on to the wish not to bother people around them while estimating the progress of the cancer condition.

\subsection{Description of Final Labels and Symbolic Wording}

Table 2 shows final labels of 7 symbolic wording extracted by the analysis. Final labels are expressed in "bold italic", the narratives of participants are in "italic", and the ID codes of the participants in brackets (ID).

1) Cooperative relationship with medical professionals

The final label of the symbolic wording here is: Patients sometimes experience gaps and differences in their perception of matters from the perceptions of the medical professionals. However, from the compassionate behaviors of the medical professionals such as expressing understanding of the conditions of the pain and answering questions about the analgesic medication, participants felt a relationship with the medical professionals sharing the wishes and ideas of the patients.

"I felt scared when I heard the word morphine for the first time, but my doctor told me that it is a commonly used medicine. I still wondered whether it is acceptable, but I did not ask the doctor about it (ID: K)". 
Table 2. Symbolic wording and final labels of self-management for cancer pain among adult outpatients.

\begin{tabular}{|c|c|}
\hline Symbolic wording & Final label \\
\hline $\begin{array}{l}\text { Cooperative relationship } \\
\text { with medical professionals }\end{array}$ & $\begin{array}{l}\text { Patients sometimes experience gaps and differences in their perception } \\
\text { of matters from the perceptions of the medical professionals. However, } \\
\text { from the compassionate behaviors of the medical professionals such as } \\
\text { expressing understanding of the conditions of the pain and answering } \\
\text { questions about the analgesic medication, participants felt a } \\
\text { relationship with the medical professionals sharing the wishes and } \\
\text { ideas of the patients. }\end{array}$ \\
\hline $\begin{array}{l}\text { Problems originating from } \\
\text { cancer pain }\end{array}$ & $\begin{array}{l}\text { Patients had trouble in movement, housework, family's care, in } \\
\text { working-due to the pain, and they suffered from impediments in } \\
\text { their daily life due to constipation and drowsiness which are side } \\
\text { effects of opioid analgesics. }\end{array}$ \\
\hline $\begin{array}{l}\text { Self-regulation of analgesic } \\
\text { medications based on the } \\
\text { interactions with medical } \\
\text { professionals }\end{array}$ & $\begin{array}{l}\text { Patients told the medical professionals of their pain conditions by } \\
\text { trying to express the felt pain effectively and also keeping a pain diary, } \\
\text { and accepted the explanations and advice on opioid analgesics from } \\
\text { the medical professionals. Following the advice, patients had taken } \\
\text { measures against side effects by regulating the dose and time of the } \\
\text { analgesic medication in conformity to their daily activities at home or } \\
\text { at the workplace. }\end{array}$ \\
\hline $\begin{array}{l}\text { Self-regulation of the } \\
\text { analgesic medications } \\
\text { based on the physical } \\
\text { perceptions of the effects }\end{array}$ & $\begin{array}{l}\text { Patients tried to avoid taking analgesics aimlessly and increasing } \\
\text { the dose because they had concerns about the resistance to opioid } \\
\text { analgesics, and the idea that the medicine itself is not good for their } \\
\text { health. From these reasons, they regulated the dose administering it } \\
\text { sparingly according to their tolerance to pain and depending on their } \\
\text { physical perceptions. }\end{array}$ \\
\hline $\begin{array}{l}\text { Self-regulation to maintain } \\
\text { a balanced and calm mind }\end{array}$ & $\begin{array}{l}\text { Due to the experiences that the mental state affects how pain is } \\
\text { perceived, patients tried to maintain calm by sharing the hardship } \\
\text { with people suffering from the same disease, switching their } \\
\text { thoughts to positive, and finding the purpose to live. }\end{array}$ \\
\hline $\begin{array}{l}\text { Fulfilling life by the pain } \\
\text { alleviation and liberation } \\
\text { from the restrictions } \\
\text { imposed by the cancer }\end{array}$ & $\begin{array}{l}\text { Patients had thought that ordinary life and meaningful time will } \\
\text { return, and the perception that they are restricted by cancer if pain } \\
\text { is alleviated. }\end{array}$ \\
\hline $\begin{array}{l}\text { Efforts to maintain their } \\
\text { lives by themselves }\end{array}$ & $\begin{array}{l}\text { Because patients do not want to impose a burden on their families } \\
\text { and people around them, they are prepared to put up with the } \\
\text { progress of the cancer condition and the increase in the pain by } \\
\text { acting courageously, trying to do their best in what they can do, } \\
\text { entrusting housework and work to others, booking hospices, and } \\
\text { renovating house. }\end{array}$ \\
\hline
\end{tabular}

Now I receive consultations from two doctors, a physician and a radiologist. I am satisfied with this relationship because I can ask the doctors questions without hesitation and they answer me properly (ID: E)".

"(Opioid analgesics) is the prescription for when I had worst pain. After that, the pain was relieved and became moderate. So I told my doctor that I do not need the same dose of the analgesic medicine. The doctor accepted my opinion and reduced the analgesics dose, (ID: J)".

"Outpatient nurses speak to me when we meet in the hallways, and they know 
my pain conditions. They share such information among nurses (ID: M)."

2) Problems originating from cancer pain

The final label of the symbolic wording here is: Patients had trouble in movement, housework, family's care, in working-due to the pain, and they suffered from impediments in their daily life due to constipation and drowsiness which are side effects of opioid analgesics.

"I cannot use the vacuum cleaner because it is heavy, I cannot do laundry because I cannot climb the stairs, and I am afraid to go shopping alone. My husband and son began to help me (ID: K)."

"I worked in the transport business and I had to carry heavy luggage. So it was impossible to continue working (ID: D)."

"I originally liked going out, but I somehow came to feel it tiresome and troublesome (ID: B)."

"I take laxatives to prevent constipation. I have trouble when going out because I worry about incontinence (ID: D)."

"I went to the hospital by car to receive an edema treatment. I was so sleepy, and I was drifting. I was driving thinking that it was dangerous (ID: M)."

3) Self-regulation of analgesic medications based on the interactions with medical professionals

The final label of the symbolic wording here is: Patients told the medical professionals of their pain conditions by trying to express the felt pain effectively and also keeping a pain diary, and accepted the explanations and advice on opioid analgesics from the medical professionals. Following the advice, patients had taken measures against side effects by regulating the dose and time of the analgesic medication in conformity to their daily activities at home or at the workplace.

"I have no other person I can depend on easily, telling them it hurts again and again, appealingly. I know the pain will not disappear even if I could depend on someone else. There is no other way than to alleviate the pain I feel by myself. In other words, I have to put up with the pain or take analgesics (ID: M)."

"My wife thinks I should do what the physician says. The pain is my problem (ID: A)."

"Because I was not able to express my pain as anything but pain, I told my doctor I am in pain, but my doctor does not know what my pain is like (ID: J)."

"Like blood pressure and weight, I record the time to take the rapid-onset opioid in my diary. I show the diary to my doctor and ask him questions in his office. With the diary, my doctor asks me, "Would you like to try a stronger analgesic medication?", or "Do you want to reduce the dose of the medication because there are side effects?" So, recording the time to take medicine in the diary is useful for both of us (ID: G)."

"When I told a nurse that I did not know the timing for when to take the rapid-onset opioid because pain appeared only when I rolled over in my sleep, the nurse advised me to take the medicine before going to bed as a preventive measure. Then I took the rapid-onset opioid following the advice, and I did not have 
the pain (ID: J)."

"Because the drowsiness from opioid analgesics is stronger than that with other medicine, I usually try to take short breaks at work, and keep my eyes closed in the rest room (ID: F)."

4) Self-regulation of the analgesic medications based on the physical perceptions of the effects

The final label of this symbolic wording here is: Patients tried to avoid taking analgesics aimlessly and increasing the dose because they had concerns about the resistance to opioid analgesics, and the idea that the medicine itself is not good for their health. From these reasons, they regulated the dose administering it sparingly according to their tolerance to pain and depending on their physical perceptions.

"When I take rapid-onset opioid, it will alleviate my pain. But it does not work as soon as it used to. I suppose it means my sensitivity has been paralyzed. I also think I need to take a pain pill that is a bit stronger (ID: A)."

" $P m$ always thinking that I don't need to take analgesics for the pain of this level, or that I should ask my doctor to change my medicine, instead of just taking the medicine that was prescribed without fully considering my situation (ID: $\mathrm{G})$."

"My primary desire is to avoid taking analgesics, that may just be my illusion, but I think that I feel better when not taking the analgesics, and because I will be released from taking analgesics and not just forgetting to take it (ID: L)."

"Because my body has become too well accustomed to painful conditions, I have decided myself that this level of pain is not the range I call pain. Cancer have spread to various parts in my body. When it hurts, I say to myself that I am still $O K$ while massaging my body. I mean, I try to take rapid-onset opioid only when the pain is strong (ID: M)."

5) Self-regulation to maintain a balanced and calm mind

The final label of this symbolic wording here is: Due to the experiences that the mental state affects how pain is perceived, patients tried to maintain calm by sharing the hardship with people suffering from the same disease, switching their thoughts to positive, and finding the purpose to live.

"Even when pain increases, I sometimes do not feel pain during business meetings. For the human body, mental power often exceeds physical power (ID: B)."

"The goals were to attend the athletic meetings and graduation ceremonies of my children. I tried hard and attended the events even though it involved a lot of trouble, (some phrases omitted) I became cheerful and felt that I could put up with the pain (ID: M)."

"I participate in the cancer salon once a month. I usually live happily but sometimes have an urge to chat with other people, because if it is a person with the same disease, we can understand each other (ID: J)."

"Well, it is better to have no pain, but I try to think about it positively that it 
hurts because I am alive (ID: L)."

6) Fulfilling life by the pain alleviation and liberation from the restrictions imposed by the cancer

The final label of this symbolic wording here is: Patients had thought that ordinary life and meaningful time will return, and the perception that they are restricted by cancer if pain is alleviated.

"I never thought of being liberated from pain, at first. Now I have time to spend with family, and feel that as meaningful time, which I once thought had been lost, has come back (ID: P)."

"I do not always feel the pain. Because there is a time when I can eat and drink as usual, I can manage to do with the present degree of pain. My remaining life expectancy may be short, but now I am fine and lead an ordinary life. I do not feel that my condition is really serious (ID: K)."

7) Efforts to maintain their lives by themselves

The final label of this symbolic wording here is: Because patients do not want to impose a burden on their families and people around them, they are prepared to put up with the progress of the cancer condition and the increase in the pain by acting courageously, trying to do their best in what they can do, entrusting housework and work to others, booking hospices, and renovating house.

"When I said to my daughter, 'it hurts, it hurts', she replied that she would be in pain when I told her it hurts. So I try not to show a painful face to my family as far as it is possible for me (ID: I)."

"It feel it most comfortable when staying in bed. But because this makes me bedridden, I try to sit up, walk, and go to a karaoke shop as much as possible. After all I have to try to move my body consciously (ID: A)."

"Because I do not want my daughter to experience hardship due to caring for me, I live on my own (ID: O)."

"P $m$ always thinking about whether I should have had someone take over my work earlier, let me leave the post I am in, or move me to a less stressful department If I cause my colleagues problems in the future (ID: F)."

"I felt I would get into trouble when I could not walk because of pain. I have coped with the disease so far, but when I found myself unable to walk, I wished to enter the hospice at last, so I made a reservation (ID: O)."

\section{Discussion}

\subsection{Formation of a Cooperative Relationship with Medical Professionals}

The results here found that self-management for cancer pain in adult outpatients was based on a cooperative relationship with medical professionals. Cancer pain is unpredictable compared to the chronic pain of non-cancer patients because the intensity and quality of cancer pain changes irregularly [17], and it is difficult for others to understand the pain as illustrated by the statements of pa- 
tients, "You (the doctor) cannot imagine how the pain is." Further, neuropathic pain that is difficult to remove may occur together with nociceptive pain, and multiple medications such as non-opioid analgesics (aspirin or acetaminophen), opioid analgesics and adjuvant analgesics are used in combination. There is also a statistically significant correlation between the intensity of cancer pain and mental health [11], and the results from the present study also show that the mental state affects how the pain is perceived. It is difficult to manage cancer pain because it is complicated as described above, and it is not easy for patients to control the pain in accordance with their lives at home or at work while performing their social roles. Further, outpatients are under time constraints in the consultation visits. For this reason, it is necessary for patients to interact with medical professionals by telling them the pain conditions exhaustively and compactly, asking questions, and having consultations to hear explanations and advice during the short outpatient consultation opportunities. McCorkle et al. [4] have reported that it is important for cancer patients to make self-management plans and carry out the plans by improving productive interactions through the partnership with medical professionals. This suggests that it is necessary for patients to form a cooperative relationship with medical professionals who enable productive interaction with medical professionals as a basis of self-management for cancer pain.

Further, because the cooperative relationship with medical professionals is also a relationship to share their wishes and thoughts, patients need to have communication skills to interact with medical professionals. Improving communication with medical professionals has been reported to lead to the building of trust relationships, self-management of cancer pain, and alleviation of psychological distress [18]. If patients can communicate their wishes and thoughts by themselves and talk with medical professionals, this may facilitate the formation of the cooperative relationship with medical professionals.

\subsection{Coping with Physical and Mental Aspects Depending on Patient Social Activities}

It was found that adult outpatients coped with problems originating from cancer pain from both the physical and mental aspects. Patients regulated themselves to maintain a balanced and calm mind by thinking positively, and finding a purpose to live. The report that there is a significant correlation between pain intensity and debilitating thoughts as well as negative emotions [19] may suggest that switching to positive thinking leads to the relief of pain, and finding a purpose to live leads to hope or motivation to live under the conditions where the patient social role changes while struggling with the pain.

Patients conducted self-regulation of analgesic medications based on the interacions with medical professionals by telling the medical professionals about their pain conditions and trying to solicit advice suitable to themselves, and the key to these efforts is the self-monitoring of pain. As the effects of opioid analgesics vary greatly among individuals, physicians prescribe opioid analgesics 
beginning with small amounts and gradually increase doses while confirming side effects and analgesic effects [20]. Further, by listening to patient self-monitoring, physicians can gain insight into the relationship between pain changes, analgesics, side effects, and activities of daily living, and determine how to proceed with managing the pain [21]. For this reason, reports of self-monitoring of the effects and side effects of analgesics by patients can be an indicator for adjusting dosages to be used by medical professionals, and encourage self-coping at home. Therefore, self-monitoring of pain may be considered important for self-regulation of analgesics administration based on the report the patient provides.

Patients conducted self-regulation of the analgesic medications based on the physical perceptions of the effects by carefully limiting the analgesic medication doses according to their tolerance to pain. The researcher infers that in the background to this sparing use of analgesic medication there may be different counteracting concerns: one that they should take the medication just following the advice of the physician, but also that if the pain is tolerable, they want to avoid analgesic medications as much as possible. This is because patients have concerns about dependence, tolerance, and side effects of opioid analgesics [5], and have become aware of the effects of the cancer by taking opioid analgesics. Patients may wish to regulate analgesic medication based on their own physical perceptions of pain, as well as decide the dosages of analgesic medications based on the awareness of the medication and their own emotional condition. These may suggest that the self-management for cancer pain needs coping that considers both the physical and mental conditions of the patients.

In addition, patients made efforts to maintain their lives by themselves trying not to impose burdens on their family and colleagues while estimating the progress of the cancer condition. This effort may embody the desire of adult patients who have social roles to fulfill, wishing to maintain an autonomous existence until the end of life. With the awareness of death, people try to avoid considering this, but it becomes an active concern when they finally recognize death as a certain reality [22]. Patients may be able to prepare for life according to their role by entrusting housework and work to others, booking hospices, and renovating the house, when they actively work to foresee the progress of their disease. As in the statement of patients that they do not want to cause trouble for their daughter shows, patients wanted to decide and conduct things by themselves rather than asking others for help. This may be because housework and childcare are difficult to leave to others, and because it is difficult to ask family members for help if the spouse is employed and children are still students in school. At the same time, however, continuing to play their social role as far as possible for patients can be an opportunity for them to reassure themselves of the value of their existence.

In addition, making efforts to maintain their lives by themselves was led by fulfilling life by the pain alleviation and liberation from the restrictions imposed by the cancer. It can be inferred that patients were able to face what 
they had to do in the future because they gained a secure confidence in pain management, thinking that they may be able to solve problems based on the experience that their efforts have led to the relief of pain and a fulfilling life. This indicates that self-efficacy has been enhanced through an experience that met with success. It is reported that self-management among patients with cancer pain will improve as self-efficacy increases [23]. This would suggest the importance for patients to improve the sense of self-efficacy through improving self-management of the cancer pain.

\subsection{Suggestions for Nursing Practice}

Patients participating in this study were self-regulating the analgesic medications, and it has been reported that the antecedents of self -management of cancer pain were physical functions, cognitive abilities, motivation, undergoing medical treatment for pain, receiving individualized training, subject to support by family and healthcare professionals, and in possession of health literacy [12]. Considering this, it is considered that it may be difficult for all outpatients with cancer pain to be able to adapt to self-management of cancer pain. Nurses assess the state over a patient's physical functions, cognitive abilities, medical treatment for pain, motivation to conduct pain management, and possession of health literacy, before performing educational activities with a patient with cancer pain. According to the result of this assessment, nurses need to conduct and perform nursing intervention to ensure promotion of self-management of the cancer pain.

It was found that patients conducted self-management for cancer pain based on the cooperative relationship with medical professionals, which enables patients to share their wishes and thoughts with the medical professionals. To build a cooperative relationship with medical professionals, it may be important for nurses to attend patients in a compassionate manner, enabling exchange of opinions. This attitude of nurse encourages a patient to tell about the experience of cancer pain, and the recognition and requests for pain management to medical professionals. In addition, it is reported that having discussions and making decisions on how nurses and patients manage pain will lead to effective self-management [10]. Therefore, nurses share the details of the purpose of the cancer pain, asking what kind of life the patient wishes to regain, and balancing the expectations and the request for pain-management. Further, nurses need to discuss particulars of the analgesic medications with the patients, and need to present it positively in the patient's life. When the needs for patient pain management are increased through such a dialog, it is considered that a patient makes decisions of the own pain management. However, it is a challenge for patients who feel tense or hesitation toward medical professionals for them to convey their wishes and thoughts. In addition, the medical professionals may have thoroughly appreciated and understood the state of the pain and the needs of the pain management, in that Japanese patients display a tendency to engage 
in an indirect communication style which uses nonverbal communication [24]. Therefore, it is important to provide patients with communication skill education that enables interaction with medical professionals.

Patients performed self-regulation of analgesic medications based on the interaction with the medical professionals, and the self-monitoring of pain by patients was important in this effort. The self-monitoring of pain serves as an indicator for analyzing the relevance of the timing of administration of analgesics, or actions to affect life, and the state of the pain. Based on the results of the self-monitoring, the patient state of mind, and the daily life of patients with cancer pain can be improved if patients analyze the factors of an insufficient pain management with medical professionals and can carry out the best pain relief measures with a clear understanding of the implications. This shows the importance of providing patients with skill training to know and regulate analgesic medications based on the results of self-monitoring for pain. Nurses need to evaluate whether pain has not exceeded the pain tolerance level set by patients, and whether there are obstacles to pain in the social activities of the patient, here, it is important for nurses to understand the differences in perceptions of analgesic medications that patients have without rejecting by showing understanding of the reactions of patients wanting to reduce doses of medications. When patients reduce the dose of medications and it has interfered with daily life, nurses need to explain the damage caused by neglecting the pain to patients, and need to lead patients to an optimally acceptable use of opioid analgesics. Further, as patients regulated themselves to maintain a balanced and calm mind, nurses can provide opportunities for patients to spend their lives calmly. However, some of the results from this study show a decline in motivation, suggesting the possibility that the response to the pain of patients may remain inadequate. Therefore, it is important for nurses to reconsider the pain management plans by considering whether patients are able to deal with the pain by themselves. Finally, patients showed a wish to do what they are able do by themselves. Nurses need to think with their patients about reaching an understanding with their families and people around them at the earliest possible time so that patients can receive assistance, if necessary, from the people around them, while taking care to ensure respect of the wishes of the patients.

\subsection{Limitations and Issues for the Future}

One notable limitation of the present study is that many of the primary sites of the cancer of the participants are lungs and breasts. For the future there is a need to expand the coverage to different cancer types, and clarify the self-management issues and possibilities in varied social activities. Interventions for patients with chronic diseases such as diabetes that promote self-management have been established, but efforts to provide interventions for cancer patients have only just become an issue that is attracting attention [25]. It is an urgent object for us to continue the research, and examine specific support situations to improve 
self-management of cancer pain among adult outpatients, based on the suggestions for nursing practices determined and identified in this study.

\section{Conclusion}

The findings show that self-management of cancer pain in adult outpatients involves self-coping considering both physical and mental aspects, such as regulating analgesic medications and maintaining stable states of mind based on a cooperative relationship with medical professionals, to solve problems arising from cancer pain. For this to be achieved in nursing practices, it is necessary for nurses to establish and build a cooperative relationship with patients, provide patients with communication skill education that enables them to interact with medical professionals, encourage patients to cope with the pain, both the physical and mental aspects, and help patients maintain their lives in conformity to their life roles.

\section{Acknowledgements}

I am thankful to all the participants who participated in this research. And, I am thankful also to the staff of the hospital which cooperated in data collection. In advancing this research, I am thankful to Professor Kumi Suzuki, Professor Fumiko Michishige, Professor Takaharu Araki, and other teachers of the Osaka Medical College, Faculty of Nursing which guided and encouraged me.

There is no conflict of interests which I should disclose. This work was financially supported by JSPS KAKENHI(C) Grant Number JP16K12084.

\section{Conflicts of Interest}

The author declares no conflicts of interest regarding the publication of this paper.

\section{References}

[1] Yamagishi, A., Morita, T., Miyashita, M., Igarashi, A., Akiyama, M., Akizuki, N., et al. (2012) Pain Intensity, Quality of Life, Quality of Palliative Care, and Satisfaction in Outpatients with Metastatic or Recurrent Cancer: A Japanese, Nationwide, Region-Based, Multicenter Survey. Journal of Pain and Symptom Management, 43, 503-514. https://doi.org/10.1016/j.jpainsymman.2011.04.025

[2] Sakakibara, N., Higashi, T., Yamashita, I., Miura, H., Yoshimoto, T., Yoshida, S., et al. (2015) Current Status of Pain Control for Older Cancer Patients in Comparison to Younger Patients in Outpatient and Inpatient Settings: A Report from One Prefectural Cancer Care Hospital. Palliative Care Research, 10, 135-141. (In Japanese)

[3] Knobf, M.T., Cooley, M.E., Duffy, S., Doorenbos, A., Eaton, L., Given, B., et al. (2015) The 2014-2018 Oncology Nursing Society Research Agenda. Oncology Nursing Forum, 42, 450-465. https://doi.org/10.1188/15.ONF.450-465

[4] McCorkle, R., Ercolano, E., Lazenby, M., Schulman-Green, D., Schilling, L.S., Lorig, K. and Wagner, E.H. (2011) Self-Management: Enabling and Empowering Patients Living with Cancer as a Chronic Illness. A Cancer Journal for Clinicians, 61, 50-62. https://doi.org/10.3322/caac.20093

[5] Naveh, P., Leshem, R., Dror, Y.F. and Musgrave, C.F. (2011) Pain Severity, Satisfac- 
tion with Pain Management, and Patient-Related Barriers to Pain Management in Patients with Cancer in Israel. Oncology Nursing Forum, 38, E305-E313. https://doi.org/10.1188/11.ONF.E305-E313

[6] Reid, C.M., Gooberman-Hill, R. and Hanks, G.W. (2008) Opioid Analgesics for Cancer Pain: Symptom Control for the Living or Comfort for the Dying? A Qualitative Study to Investigate the Factors Influencing the Decision to Accept Morphine for Pain Caused by Cancer. Annals of Oncology, 19, 44-48.

https://doi.org/10.1093/annonc/mdm462

[7] Liang, S.Y., Chen, K.P., Tsay, S.L., Wu, S.F., Chuang, Y.H., Wang, T.J. et al. (2013) Relationship between Belief About Analgesics, Analgesic Adherence and Pain Experience in Taiwanese Cancer Outpatients. Asian Pacific Journal of Cancer Prevention, 14, 713-716. https://doi.org/10.7314/APJCP.2013.14.2.713

[8] Hiraoka, R. and Sato, R. (2012) Independent Grappling with Pain Management of Cancer Patients. Journal of Japanese Society of Cancer Nursing, 26, 23-33. (In Japanese)

[9] Schumacher, K.L., Plano Clark, V.L., West, C.M., Dodd, M.J., Rabow, M.W. and Miaskowski, C. (2014) Pain Medication Management Processes Used by Oncology Outpatients and Family Caregivers Part II: Home and Lifestyle Contexts. Journal of Pain and Symptom Management, 48, 784-796. https://doi.org/10.1016/j.jpainsymman.2013.12.247

[10] Hughes, N.D., Closs, S.J., Flemming, K. and Bennett, M.I. (2016) Supporting Self-Management of Pain by Patients with Advanced Cancer: Views of Palliative Care Professionals. Support Care Cancer, 24, 5049-5057. https://doi.org/10.1007/s00520-016-3372-2

[11] Takeda, N. and Onishi, K. (2009) The Relationship between Cancer Pain and QOL for Cancer Patients. Mie Nursing Journal, 11, 19-27. (In Japanese)

[12] Yamanaka, M. (2018) A Concept Analysis of Self-Management of Cancer Pain. Asia-Pacific Journal of Oncology Nursing, 5, 254-261. https://doi.org/10.4103/apjon.apjon_17_18

[13] Yamaura, H. (2012) Introduction to the Qualitative Synthesis Method of KJ Ho-Overview and Procedures. Igaku-Shoin Ltd., Tokyo. (In Japanese)

[14] Scupin, R. (1997) The KJ Method: A Technique for Analyzing Date Derived from Japanese Ethnology. Human Organization, 56, 233-237. https://doi.org/10.17730/humo.56.2.x335923511444655

[15] Nomura, T., Kunifuji, S., Naganobu, M., Maruyama, S. and Miura, M. (2013) Introduction to KJ-Ho: A Japanese Problem Solving Approach.

https://www.creativityjournal.net/newsevents/item/201-kj-ho-japanese-problem-sol ving\#.W6ruPORReUk

[16] Shenton, A.K. (2004) Strategies for Ensuring Trustworthiness in Qualitative Research Projects. Education for Information, 22, 63-75. https://doi.org/10.3233/EFI-2004-22201

[17] Koyama, N. (2010) Basic Knowledge of Pain and Painkilling. Gijutsu-Hyohron, Tokyo. (In Japanese)

[18] Janjan, N. (2014) Improving Cancer Pain Control with NCCN Guideline-Based Analgesic Administration: A Patient-Centered Outcome. Journal of the National Comprehensive Cancer Network, 12, 1243-1249. https://doi.org/10.6004/jnccn.2014.0122

[19] Buck, R. and Morley, S. (2006) A Daily Process Design Study of Attentional Pain 
Control Strategies in the Self-Management of Cancer Pain. European Journal of Pain, 10, 385-398. https://doi.org/10.1016/j.ejpain.2005.04.001

[20] Japanese Society for Palliative Medicine (2014) Clinical Guideline for Cancer Pain Management. Kanehara \& Co., Tokyo. (In Japanese)

[21] Hochstenbach, L.M.J., Zwakhalen, S.M.G., Courtens, A.M., van Kleef, M. and de Witte, L.P. (2016) Feasibility of a Mobile and Web-Based Intervention to Support Self-Management in Outpatients with Cancer Pain. European Journal of Oncology Nursing, 23, 97-105. https://doi.org/10.1016/j.ejon.2016.03.009

[22] Kikui, K. and Takeda, K. (2000) Reflections on Acceptance of Death-Japanese Concept and Behavior. Kawasaki Medical Welfare Journal, 10, 63-70. (In Japanese)

[23] Koller, A., Miaskowski, C., De Geest, S., Opitz, O. and Spichiger, E. (2013) Results of a Randomized Controlled Pilot Study of a Self-Management Intervention for Cancer Pain. European Journal of Oncology Nursing, 17, 284-291. https://doi.org/10.1016/j.ejon.2012.08.002

[24] Kawai, N., Sugaya, A., Morino, A., Imaizumi, K., Yanaida, K., Sakai, S., et al. (2007) Cultural Features of Japan in Healthcare Described in Overseas Literatures. Journal of Chiba Academy of Nursing Science, 13, 119-127. (In Japanese)

[25] Lovell, M.R., Luckett, T., Boyle, F.M., Phillips, J., Agar, M. and Davidson, P.M. (2014) Patient Education, Coaching, and Self-Management for Cancer Pain. Journal of Clinical Oncology, 32, 1712-1720. https://doi.org/10.1200/JCO.2013.52.4850 